\title{
Assessment of Price Risk of Power under Indian Electricity Market
}

\author{
Sandeep Chawda \\ Assistant Profesor \\ JSPM's BSIOTR (W) \\ Wagholi, Pune (INDIA)
}

\author{
S. Deshmukh, PhD. \\ Associate Professor \\ PVG's COET \\ Parvati, Pune (INDIA)
}

\begin{abstract}
Abstract: In order to promote competition in Indian Electricity Market as per Indian Electricity Act 2003, Power Exchanges are established and running successfully since 2008. Power exchange is an electronic exchange which provides a common place for electricity trading. Price of electricity is more volatile than any other commodity. This volatile nature of electricity-price introduces risk to market participants. Hence assessment and control of risk have become essential tasks for the players in power market. In this paper Value at Risk $(\mathrm{VaR})$ \& Conditional Value at Risk (CVaR) methods are used for the assessment of price-risk. The data of Market Clearing Price (MCP) available at Indian Energy Exchange (IEX) are used for the calculation of risk. The results are discussed in detail.
\end{abstract}

\section{Keywords}

Electricity Market, Risk, Power Exchange.

\section{INTRODUCTION}

All over the world, energy markets have been, or are in the process of being restructured. Due to deregulation in power market, new uncertainties are introduced. Risk is defined as the possibility of loss, injury, disadvantage or destruction [1]. Risk is the hazard to which a market participant is exposed because of uncertainty [1]. Today, every utility is exposed to risk due to market price fluctuations (market price risk), which can have a deep impact on the income statement and balance sheet. To begin with, companies used to focus on market price risk but they soon realized other risks must be considered, including:

- Liquidity risk, which could be divided in volume and margin risk

- Credit risk, particularly worrying in OTC (over the contour) markets

- Regulatory risk

- Operational risk

The risk management issue from power systems points of view is given in [3].

This paper mainly focuses on risk due to price-volatility. The Day Ahead Market with reference to Indian Electricity Market is studied and using the data of market clearing prices (MCP) \& market clearing volume (MCV) available on Indian Energy Exchange (IEX) and Power Exchange India Limited (PXIL), the risk is evaluated at each hour using Value at Risk (VaR) \& Conditional Value at Risk (CVaR) method. The VaR and $\mathrm{CVaR}$ methods are discussed in detail in the paper. Also the algorithm of applying theses methods for calculation of risk is reported along with cases and results.

\section{RISK MANAGEMENT}

A simple way to define risk management is: The process of identifying, evaluating, and mitigating the risks that threaten the strategic and financial goals of your business. Also we can define Risk management is the process of achieving the desired balance of risk and return through a particular trading strategy [1]. In the financial literature, risk management at least includes two aspects: risk control and risk assessment as shown in Fig. 1.

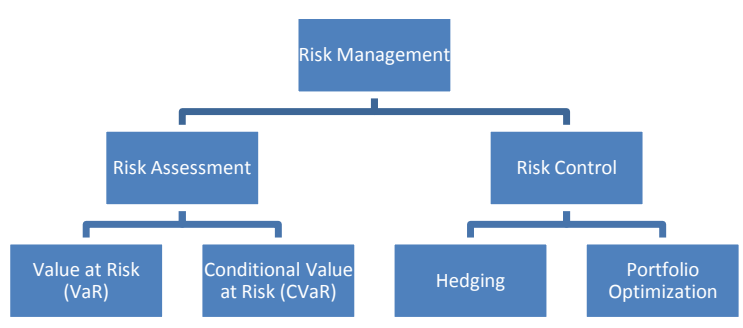

Fig. 1: Risk Management

This is why most utilities work actively on financial risk management. Although there are many strategies, such as hedging, arbitrage or speculation, most companies know what they want their 'core business' to be, so they just try to swap their risks in order to control and limit risk exposures. To achieve this, a wide variety of physical and financial contracts are currently traded in the utility markets.

There are so many risk factors which can affect the profit of an electricity producer; examples are: varying electricity and fuel prices, varying demand, equipment malfunctions and defaulted payments.

Power trading is an integral aspect of competitive power markets. By efficiently managing risk, energy trading helps to ensure reliable electricity at stable prices, and promotes transparent energy markets. Therefore, risk management tools have become more and more important in electricity generation, planning and market operations. In other words, proper risk management tool is essential for energy companies to maximize profits and survive in the market with high volatility. 


\section{RISK ASSESSMENT \& CONTROL}

For risk assessment, Value at Risk (VaR) is an effective way of measuring the risk and has been applied in electricity market [2].

\subsection{Value at Risk (VaR)}

The Global Derivatives Study Group, a former promoter of VaR, defines VaR as "the expected loss for an adverse market movement with a specified probability over a particular period of time"[2]. Essentially, VaR is a monetary value that the portfolio will lose less than that amount over a specified period of time with a specified probability.

VaR summarizes the expected maximum loss over a target horizon within a given confidence interval. VaR does not provide a measure of the potential losses exceeding the VaR value;

- Choosing a portfolio to optimize VaR may cause a stretch in the loss distribution tail which creates potential for even larger losses that exceed $\mathrm{VaR}$;

- VaR is difficult to optimize except when assuming normal distributions for underlying market variables.

A method called Conditional VaR has been preferred in recent years to overcome the listed limitations of VaR.

\subsection{Conditional Value-at-Risk}

Conditional Value-at-Risk (VaR) is also known as the mean excess loss [2]. CVaR overcomes at least one of VaR's limitations: measuring the potential losses exceeding VaR. By calculating the mean of the loss exceeding the $\mathrm{VaR}$ value, $\mathrm{CVaR}$ provides a better indication of the potential losses exceeding the assumed confidence level.

$\mathrm{CVaR}$ is defined as the conditional expectation of losses given that the loss exceeds a threshold value (VaR value).

Assessment of risk is done using historical method for a given quantity of electricity purchased from power exchange [2]. Value at risk (Var) and Conditional Value at risk (CVar) for a confidence interval of $95 \%$ and $99 \%$ are calculated, which gives risk associated with given quantity of power purchase.

\subsection{Risk Control - Hedging}

Definition of Hedge

- Using the futures or options markets to manage price risks

- A temporary substitution of a futures market transaction for a planned cash market transaction

- Taking equal and opposite positions on the cash and futures markets

Hedging is buying of a derivative to offset the risk of a cash position, which is the amount of energy owned. Derivatives are financial instruments (contracts) that do not represent ownership rights in energy but, rather, derive their value from the value of some other underlying commodity or other asset. When used prudently, derivatives are efficient and effective tools for isolating financial risk and "hedging" to reduce exposure to risk. The most commonly used derivative contracts include Forward Contracts, Futures Contracts, Options and Swaps etc. [2].

\section{POWER EXCHANGE}

Power exchange is a market place where Electricity is traded. It provides a platform to market participant where they can sell or buy electricity, where prices are decided by market itself. A power exchange contributes significantly to facilitating trade and distribution of market information, promoting competition and creation of liquidity in a deregulated power market. The day-ahead spot market provides a neutral, transparent reference price for both the wholesale and retail markets. Further,

- It provides a reference price for bilateral power trade.

- It serves as a reliable counterparty.

- It provides easy access to a physical market at low transaction costs.

- It serves as a grid congestion management tool.

- It creates the possibility of balancing portfolios close to operation.

- It distributes relevant neutral market information and

- It is a non-mandatory power exchange, as an alternative to bilateral contract trade.

Exchange operations so far Indian Energy Exchange (IEX), Delhi was the first exchange in the country to start operations, June 27, 2008. Power Exchange India Limited (PXIL), Mumbai, started operations on October 22, 2008. Both exchanges have been operating successfully. Following are the features of Indian Exchanges.

- Nation-wide, electronic exchange for trading of Power

- Exchange will handle power trading and transmission clearance simultaneously

- Transparent, neutral and efficient electronic platform

- $\quad$ Trading to start with day-ahead contracts (all 24 hours)

- No separate booking of Transmission Corridor required

- All the participants come to one single platform and get access to each other on a national basis

- Buyers and sellers can participate directly

- Exchange to guarantee payments to sellers

- Buyers - All confirmed trades on the exchange to be scheduled and deviations to be settled through unscheduled interchange (UI)

- Online Buying/Selling of Power 


\section{CALCULATION OF RISK}

\subsection{VaR Calculation of Actual Data using Historical Method}

Value at risk $(\mathrm{VaR})$ \& Conditional value at risk $(\mathrm{CVaR})$ methods are used at $95 \%$ confidence level \& $99 \%$ confidence level. Two cases are studied:

- Case - I: 10 MW power is purchased from market for whole day.

- Case - II: 285 MW power is purchased from market for whole day.

(Actually hourly MW power purchased from market will not be constant but for the sake of simplicity, the constant power transaction is assumed as $10 \mathrm{MW} \& 285 \mathrm{MW}$ ).

Algorithm for Value at Risk (Var) calculation for one hour is given in next paragraph.

\section{Algorithm}

1. Compose an array of prices representing the payment made by utility company for purchase of power for each of the 100 days each hour.

2. Calculate an array of the changes in amount of payment made by utility from the previous day's payment.

3. Order this difference values from largest positive to largest negative.

4. To compute the $99 \%$ confidence level VaR, using the historical data, a value is chosen which is greater than $99 \%$ of all losses experienced in the historical sample period.

5. The definition of $99 \%$ confidence level VaR is 'the VaR (the value) such that a given loss will exceed this value only $1 \%$ of the time'. So, the second ordered value is selected as the $\mathrm{VaR}$ at $99 \%$ confidence level.

6. The definition of $95 \%$ confidence level VaR is the VaR (the value) such that a given loss will exceed this value only $5 \%$ of the time. So, the sixth ordered value is selected as the $\mathrm{VaR}$ at $95 \%$ confidence level.

\section{Case - I: $10 \mathrm{MW}$ power is purchased from market for whole day.}

Following above algorithm value at risk is calculated for $95 \%$ and $99 \%$ confidence level. Table 1 shows the risk at $95 \%$ confidence level and at $99 \%$ confidence level for $10 \mathrm{MW}$ purchase of power from Power Exchange for 1st April 2010 for 24 hours of day.

In Table 1, Column 1 represents 24 hours for whole day. Column 2 shows the MW power purchased from power exchange for every hour. Column 3 shows the hourly spot price (collected from Indian Energy Exchange) on 1st April 2010. Column 4 shows the calculated expected cost in Rs. for purchasing $10 \mathrm{MW}$ for whole day.

Expected Cost $=$ Hourly Spot Price $\mathrm{x} 10$
Column 5 represents the hourly magnitude of risk at $95 \%$ confidence level. Column 6 gives the percentage magnitude of risk with reference to expected cost at $95 \%$ confidence level.

Column 7 and column 8 represents the hourly magnitude of risk and the percentage magnitude of risk with reference to expected cost at $99 \%$ confidence level respectively.

Table 1

VaR for 10 MW Purchase from Exchange for 1st April 2010.

\begin{tabular}{|c|c|c|c|c|c|c|c|}
\hline \multicolumn{8}{|c|}{ VaR for 10 MWP Purchase from Exchange for 1stA } \\
\hline Hour & $\begin{array}{l}\text { Volume } \\
\text { Puchased } \\
\text { from } \\
\text { Power Ex. } \\
\text { (MW) }\end{array}$ & $\begin{array}{l}\text { Spot P } \\
\text { ist ApI } \\
\text { R }\end{array}$ & (KS.) & $\begin{array}{c}\text { VaR at } 95 \% \\
\text { Confidence } \\
\text { Level (Rs.) }\end{array}$ & $\begin{array}{l}\text { Percentage } \\
\text { VaR at } 95 \% \\
\text { Confidence } \\
\text { Level } \\
\text { (Rs.) }\end{array}$ & \begin{tabular}{|c} 
VaR at $99 \%$ \\
Confidence \\
level (Rs.)
\end{tabular} & $\begin{array}{c}\text { VaR at } 99 \% \\
\text { Confidence } \\
\text { Level }\end{array}$ \\
\hline-01 & .00 & 8 & 30 & 001 & 34.53 & 0 & 01. \\
\hline $1-02$ & 10.00 & 270 & 27 & & & & 66. \\
\hline $2-03$ & 10.00 & 2906.01 & 29060.10 & 55200.96 & 189.95 & 71328.02 & 245.45 \\
\hline 3-04 & 10.00 & 2907.68 & $290^{\circ}$ & & 29. & 100 & 34. \\
\hline $4-05$ & 10.00 & 2996.57 & 29965.70 & 9995.90 & 33.36 & 15022.10 & 50.13 \\
\hline $5-06$ & 10.00 & 3000.72 & 300 & & 1 & 155 & 51. \\
\hline 06-07 & 10.00 & 4498.86 & 44988.60 & 10002.50 & 22.23 & 193 & 42.97 \\
\hline $7-08$ & 10.00 & 3991.49 & 3991 & 160 & 40.12 & 214 & 53.68 \\
\hline $8-09$ & 10.00 & 499.46 & 60 & 170 & & 175 & 38.96 \\
\hline $99-10$ & 10.00 & 4499.64 & 44996.40 & 16016.40 & 35.59 & 25023.50 & 55.61 \\
\hline $0-11$ & 10.00 & 4499.63 & 449 & 170 & 37.82 & 270 & 60.01 \\
\hline $11-12$ & 10.00 & 4489.91 & 44899.10 & 18017.00 & 40.13 & 27005.40 & 60.15 \\
\hline $12-13$ & 10.00 & 4499.22 & 44992.20 & 17503.50 & 38.90 & 27009.50 & 60.03 \\
\hline 13-14 & 10.00 & 4499.91 & 44999.10 & 15030.70 & 40 & 25020.90 & 55.60 \\
\hline 14-15 & 10.00 & 5739.44 & 57394.40 & 120 & 20.93 & 25583.60 & 44.58 \\
\hline $15-16$ & 0.00 & 5739.37 & 573 & 142 & 79 & 270 & 47.08 \\
\hline $16-17$ & 10.00 & 4499.31 & 44993.10 & 17000.80 & 37.79 & 26560.40 & 59.03 \\
\hline 17-18 & 10.00 & 4499.19 & 44991.90 & 18498.40 & 41.11 & 22638.50 & 50.32 \\
\hline $18-19$ & 10.00 & 3999.58 & 39995.80 & 15014.00 & 37.54 & 22495.60 & 56.24 \\
\hline $19-20$ & 10.00 & 4800.76 & 48007.60 & 12898.30 & 26.87 & 32005.50 & 66.67 \\
\hline $20-21$ & 10.00 & 3999.74 & 39997.40 & 10005.60 & 25.02 & 25006.70 & 62.52 \\
\hline $21-22$ & 10.00 & 3999.69 & 39996.90 & 6988.40 & 17.47 & 20016.60 & 50.05 \\
\hline $22-23$ & 10.00 & 3999.54 & 39995.40 & 12499.40 & 31.25 & 20013.30 & 50.04 \\
\hline $23-24$ & 10.00 & 3892.89 & 38928.90 & 14735.50 & 37.85 & 25992.40 & 66.77 \\
\hline & 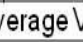 & & 40858 & 1060 & 38.62 & 2423 & 68 \\
\hline
\end{tabular}

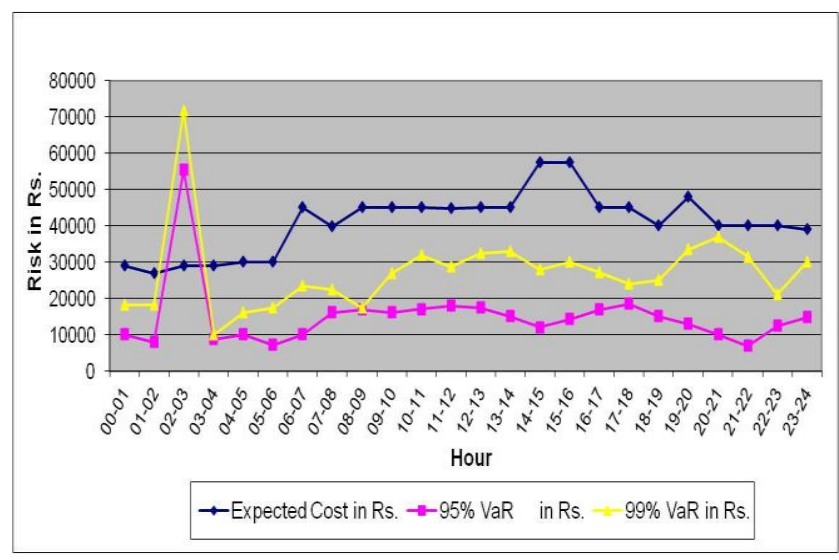

Fig. 2: VaR for 10 MW Purchase from Exchange for 1st April 2010 
It can be observed from Table 1 \& Fig. 2 that minimum spot price and maximum spot price for trading day (1st April 2010) are Rs. 2700.95 and Rs. 5739.44 respectively. The minimum value of Value at Risk at 95\% and 99\% confidence level are observed as Rs. 6988.0 and Rs. 10104.0 respectively. The maximum value of Value at Risk at $95 \%$ and $99 \%$ confidence level are observed as Rs. 55200.0 and Rs. 71593.0 respectively. Daily average percentage $\mathrm{VaR}$ at $95 \%$ confidence level are $38.6 \%$ and at $99 \%$ confidence level is $61.6 \%$. If utility company blindly goes for trading, company is imposing to a huge amount of risk.

\section{Case - II: 285 MW power is purchased from market for} whole day.

Following the same algorithm, the magnitude of risk is calculated for purchase of 285 MW power from power exchange on 1st April 2010 for whole day. Table 2 shows the result.

It can be observe from Table $2 \&$ Fig. 3 that minimum spot price and maximum spot price for trading day (1st April 2010) are Rs. 2700.95 and Rs. 5739.44 respectively. The minimum value of Value at Risk at $95 \%$ and $99 \%$ confidence level are observed as Rs. 191947.50 and Rs. 427899.0 respectively.

Table 2

VaR for 285 MW Purchase from Exchange for 1st April 2010.

\begin{tabular}{|c|c|c|c|c|c|c|c|}
\hline \multicolumn{8}{|c|}{ VaR for 285 MWP Purchase from the Exchange for 1st April 2010} \\
\hline Hour & $\begin{array}{l}\text { Volume } \\
\text { Puchlased } \\
\text { from } \\
\text { Power Ex. } \\
\text { (MW) }\end{array}$ & $\begin{array}{l}\text { Spot Price on } \\
\text { 1st April } \\
2010 \\
\text { (Rs.) }\end{array}$ & $\begin{array}{l}\text { Expected Cost = } \\
\text { Spot Price } 285 \\
\text { (Rs.) }\end{array}$ & $\begin{array}{c}\text { VaR at } 95 \% \\
\text { Confidence Level } \\
\text { (Rs.) }\end{array}$ & $\begin{array}{c}\text { Percentag } \\
\text { e VaR at } \\
95 \% \\
\text { Confidenc } \\
\text { e Level } \\
\text { (Rs.) }\end{array}$ & $\begin{array}{c}\text { VaR at } 99 \% \\
\text { Confidence level } \\
\text { (Rs.) }\end{array}$ & $\begin{array}{c}\text { Percentag } \\
\text { eVaR at } \\
99 \% \\
\text { Confidenc } \\
\text { eLevel } \\
\end{array}$ \\
\hline 00-01 & 285 & 2901.68 & 826978.80 & 208990.50 & 25.27 & 427899.00 & 51.74 \\
\hline $01-02$ & 285 & 2700.95 & 769770.75 & 203746.50 & 26.47 & 513208.05 & 66.67 \\
\hline $02-03$ & 285 & 2906.01 & 828212.85 & 191947.50 & 23.18 & 285059.85 & 34.42 \\
\hline 03-04 & 285 & 2907.68 & 828688.80 & 227905.95 & 27.50 & 285259.35 & 34.42 \\
\hline $04-05$ & 285 & 2996.57 & 854022.45 & 271054.95 & 31.74 & 428129.85 & 50.13 \\
\hline 05-06 & 285 & 3000.72 & 855205.20 & 200164.05 & 23.41 & 441992.25 & 51.68 \\
\hline 06-07 & 285 & 4498.86 & 1282175.10 & 213895.35 & 16.68 & 550887.90 & 42.97 \\
\hline $07-08$ & 285 & 3991.49 & 1137574.65 & 455452.80 & 40.04 & 610698.00 & 53.68 \\
\hline $08-09$ & 285 & 4499.46 & 1282346.10 & 470369.70 & 36.68 & 498809.85 & 38.90 \\
\hline $09-10$ & 285 & 4499.64 & 1282397.40 & 427420.20 & 33.33 & 713169.75 & 55.61 \\
\hline $10-11$ & 285 & 4499.63 & 1282394.55 & 384613.20 & 29.99 & 769576.95 & 60.01 \\
\hline $11-12$ & 285 & 4489.91 & 1279624.35 & 513285.00 & 40.11 & 769653.90 & 60.15 \\
\hline $12-13$ & 285 & 4499.22 & 1282277.70 & 410174.85 & 31.99 & 769770.75 & 60.03 \\
\hline $13-14$ & 285 & 4499.91 & 1282474.35 & 426710.55 & 33.27 & 713095.65 & 55.60 \\
\hline $14-15$ & 285 & 5739.44 & 1635740.40 & 341532.60 & 20.88 & 729132.60 & 44.58 \\
\hline $15-16$ & 285 & 5739.37 & 1635720.45 & 385311.45 & 23.56 & 770027.25 & 47.08 \\
\hline $16-17$ & 285 & 4499.31 & 1282303.35 & 427616.85 & 33.35 & 756971.40 & 59.03 \\
\hline $17-18$ & 285 & 4499.19 & 1282269.15 & 427719.45 & 33.36 & 645197.25 & 50.32 \\
\hline $18-19$ & 285 & 3999.58 & 1139880.30 & 427899.00 & 37.54 & 641124.60 & 56.24 \\
\hline $19-20$ & 285 & 4800.76 & 1368216.60 & 367601.55 & 26.87 & 912156.75 & 66.67 \\
\hline $20-21$ & 285 & 3999.74 & 1139925.90 & 285159.60 & 25.02 & 712690.95 & 62.52 \\
\hline $21-22$ & 285 & 3999.69 & 1139911.65 & 199169.40 & 17.47 & 570473.10 & 50.05 \\
\hline $22-23$ & 285 & 3999.54 & 1139868.90 & 356232.90 & 31.25 & 570379.05 & 50.04 \\
\hline $23-24$ & 285 & 3892.89 & 1109473.65 & 407381.85 & 36.72 & 740783.40 & 66.77 \\
\hline \multicolumn{3}{|c|}{ Average Value } & 1164477.23 & 342973.16 & 29.40 & 617756.14 & 52.89 \\
\hline
\end{tabular}

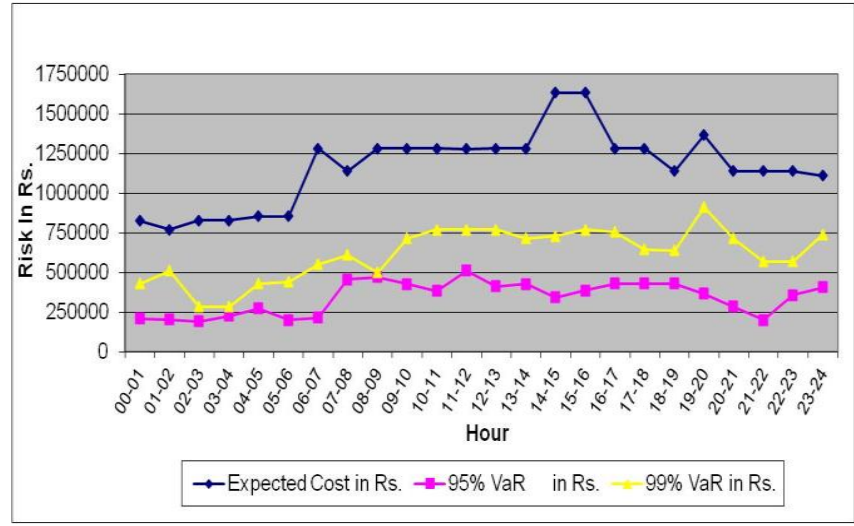

Fig. 3: Var for 285 MW Purchase from Exchange for 1st April 2010

The maximum value of Value at Risk at $95 \%$ and $99 \%$ confidence level are observed as Rs. 513285.0 and Rs. 912156.75 respectively. Daily average percentage $\mathrm{VaR}$ at $95 \%$ confidence level are $29.40 \%$ and at $99 \%$ confidence level is $52.88 \%$. If utility company blindly goes for trading, company is imposing to a huge amount of risk.

Calculated VaR does not provide a measure of the potential losses exceeding the VaR value. Also, it may cause a stretch in the loss distribution tail which creates potential for even larger losses that exceed $\mathrm{VaR}$ value. $\mathrm{CV}$ ar method gives more accurate result and overcome limitations of $\mathrm{VaR}$.

\subsection{Calculation of Risk using Conditional Value at Risk}

The average of the six largest ordered loss values evaluated following the algorithm of $\mathrm{VaR}$ gives the $\mathrm{CVaR}$ at $95 \%$ confidence level.

As per definition of $\mathrm{CVaR}$, the $\mathrm{CVaR}$ at $99 \%$ confidence level is simply the average of the two largest ordered loss values (i.e. first two ordered value).

Same two cases are studied and CVaR is evaluated for both cases at two confidence level.

\section{Case - I: $10 \mathrm{MW}$ power is purchased from market for whole day.}

Following same algorithm of value at risk, conditional value at risk is calculated for $95 \%$ and $99 \%$ confidence level. Table 3 \& Fig. 4 shows the risk at $95 \%$ confidence level and at $99 \%$ confidence level for $10 \mathrm{MW}$ purchase of power from Power Exchange for 1st April 2010 for 24 hours of day.

In Table 3, Column 1 represents 24 hours for whole day. Column 2 shows the MW power purchased from power exchange for every hour. Column 3 shows the hourly spot price (collected from Indian Energy Exchange) on 1st April 2010. Column 4 shows the calculated expected cost in Rs. for purchasing $10 \mathrm{MW}$ for whole day. Expected Cost is given by equation 1 . 
Column 5 represents the hourly magnitude of $\mathrm{CVaR}$ at $95 \%$ confidence level. Column 6 gives the percentage magnitude of risk (CVaR) with reference to expected cost at 95\% confidence level. Column 7 and column 8 represents the hourly magnitude of $\mathrm{CVaR}$ and the percentage magnitude of $\mathrm{CVaR}$ with reference to expected cost at $99 \%$ confidence level respectively.

Table 3

CVaR for 10 MW Purchase from Exchange for 1st April 2010.

\begin{tabular}{|c|c|c|c|c|c|c|c|}
\hline \multicolumn{8}{|c|}{ CVaR for 10 MWPurchase from the Exchange for Ist April 2010} \\
\hline Hour & $\begin{array}{c}\text { Volume } \\
\text { Puchased } \\
\text { from } \\
\text { Power Ex. } \\
\text { (MW) }\end{array}$ & $\begin{array}{l}\text { Spot Price on } \\
\text { Ist April 2010 } \\
\text { (Rs.) }\end{array}$ & $\begin{array}{l}\text { Expected Cost }= \\
\text { Spot price } 10 \\
\text { (Rs.) }\end{array}$ & $\begin{array}{c}\text { CVaR at } 95 \% \\
\text { Confidence Leve } \\
\text { (Rs.) }\end{array}$ & $\begin{array}{c}\text { Percentage } \\
\text { CVaR at } \\
95 \% \\
\text { Confidence } \\
\text { Level } \\
\text { (Rs.) }\end{array}$ & $\begin{array}{l}\text { CVaR at } 99 \% \\
\text { Confidence level } \\
\text { (Rs.) }\end{array}$ & $\begin{array}{l}\text { Percentage } \\
\text { CVaR at } \\
99 \% \\
\text { Confidence } \\
\text { Level }\end{array}$ \\
\hline $00-01$ & 10 & 2901.68 & 29016.80 & 12744.55 & 43.92 & 16599.65 & 57.21 \\
\hline $01-02$ & 10 & 2700.95 & 27009.50 & 11861.45 & 43.92 & 18098.70 & 67.01 \\
\hline $02-03$ & 10 & 2906.01 & 29060.10 & 61618.68 & 212.04 & 71460.86 & 245.91 \\
\hline 03-04 & 10 & 2907.68 & 29076.80 & 9304.12 & 32.00 & 10057.00 & 34.59 \\
\hline $04-05$ & 10 & 2996.57 & 29965.70 & 12177.65 & 40.64 & 15502.70 & 51.73 \\
\hline $05-06$ & 10 & 3000.72 & 30007.20 & 10778.40 & 35.92 & 16398.30 & 54.65 \\
\hline $06-07$ & 10 & 4498.86 & 44988.60 & 15268.02 & 33.94 & 21389.05 & 47.54 \\
\hline $07-08$ & 10 & 3991.49 & 39914.90 & 18819.47 & 47.15 & 21959.30 & 55.02 \\
\hline $08-09$ & 10 & 4499.46 & 44994.60 & 17170.50 & 38.16 & 17504.15 & 38.90 \\
\hline $09-10$ & 10 & 4499.64 & 44996.40 & 20924.82 & 46.50 & 26013.95 & 57.81 \\
\hline $10-11$ & 10 & 4499.63 & 44996.30 & 22244.28 & 49.44 & 29468.85 & 65.49 \\
\hline $11-12$ & 10 & 4489.91 & 44899.10 & 22338.60 & 49.75 & 27903.70 & 62.15 \\
\hline $12-13$ & 10 & 4499.22 & 44992.20 & 22629.50 & 50.30 & 29689.15 & 65.99 \\
\hline $13-14$ & 10 & 4499.91 & 44999.10 & 20772.68 & 46.16 & 29011.80 & 64.47 \\
\hline $14-15$ & 10 & 5739.44 & 57394.40 & 17037.23 & 29.68 & 26797.55 & 46.69 \\
\hline $15-16$ & 10 & 5739.37 & 57393.70 & 20973.98 & 36.54 & 28537.45 & 49.72 \\
\hline $16-17$ & 10 & 4499.31 & 44993.10 & 22163.48 & 49.26 & 26796.55 & 59.56 \\
\hline $17-18$ & 10 & 4499.19 & 44991.90 & 19914.88 & 44.26 & 23347.10 & 51.89 \\
\hline $18-19$ & 10 & 3999.58 & 39995.80 & 20307.83 & 50.77 & 23801.00 & 59.51 \\
\hline $19-20$ & 10 & 4800.76 & 48007.60 & 23753.30 & 49.48 & 32757.25 & 68.23 \\
\hline $20-21$ & 10 & 3999.74 & 39997.40 & 22335.65 & 55.84 & 30999.80 & 77.50 \\
\hline $21-22$ & 10 & 3999.69 & 39996.90 & 15248.95 & 38.13 & 25755.45 & 64.39 \\
\hline $22-23$ & 10 & 3999.54 & 39995.40 & 18169.05 & 45.43 & 20515.35 & 51.29 \\
\hline $23-24$ & 10 & 3892.89 & 38928.90 & 19675.57 & 50.54 & 28002.30 & 71.93 \\
\hline \multicolumn{3}{|c|}{ Average Value } & 40858.85 & 19926.36 & 50.82 & 25765.29 & 65.38 \\
\hline
\end{tabular}

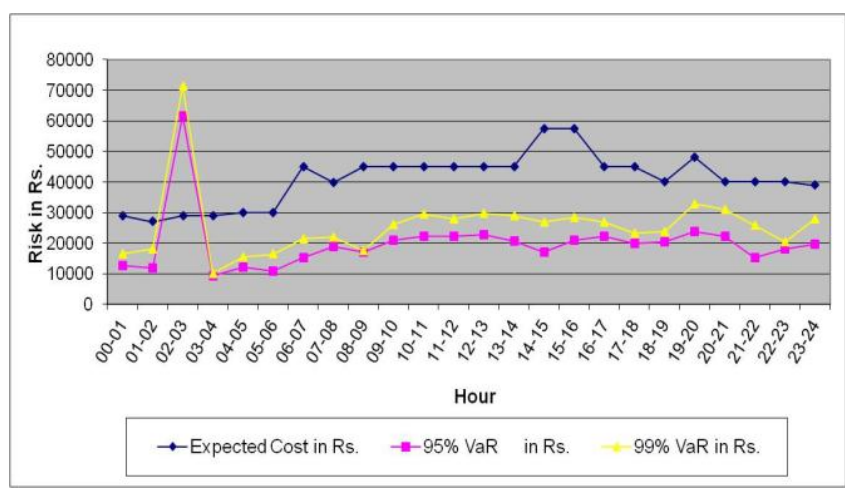

Fig. 4: CVaR for 10 MW Purchase from Exchange for $1^{\text {st }}$ April 2010.

\section{Case - II: 285 MW power is purchased from market for whole day.}

Following the same steps of calculation of $10 \mathrm{MW} \mathrm{CVaR}$, evaluation of CVaR of $285 \mathrm{MW}$ power on 1st April for same two confidence level is done. Table 4 shows the result. From Table 4 and Fig. 5, the minimum value of Conditional Value at Risk at 95\% and 99\% confidence level are observed as Rs. 259567.55 and Rs. 286624.50 respectively. The maximum value of Conditional Value at Risk at $95 \%$ and $99 \%$ confidence level are observed as Rs. 676969.05 and Rs. 933581.63 respectively. Daily average percentage CVaR at 95\% confidence level are $43.29 \%$ and at $99 \%$ confidence level is $56.93 \%$. Utility company may remove risk by adopting proper risk management strategies.

Table 4

CVaR for 285 MW Purchase from Exchange for 1st April 2010.

\begin{tabular}{|c|c|c|c|c|c|c|c|}
\hline \multicolumn{8}{|c|}{ CVaR for 285 MWP Purchase from the Exchange for 1st April2010 } \\
\hline Howr & $\begin{array}{c}\text { Volume } \\
\text { Puchased } \\
\text { from Powe } \\
\text { Ex. } \\
\text { (MWM }\end{array}$ & st $A$ & $\begin{array}{l}\operatorname{Exp} \\
\mathrm{Sp}\end{array}$ & leve & $\begin{array}{l}\text { CVaR a t95\% } \\
\text { Confidence } \\
\text { Level } \\
\text { (Rs.) }\end{array}$ & $\begin{array}{c}\text { CVaR at } 99 \% \\
\text { Confidence leve } \\
\text { (Rs.) }\end{array}$ & $\begin{array}{l}\text { CVaR at } 99 \% \\
\text { Confidence } \\
\text { Level }\end{array}$ \\
\hline $0-01$ & 285 & 01.68 & 80 & & .92 & 0.03 & 01.21 \\
\hline $1-02$ & 285 & 2700.95 & 769770.75 & 338051.33 & 43.92 & 515812.95 & 67.01 \\
\hline $02-03$ & 285 & 2906.01 & 828212.85 & 259567.55 & 31.34 & 356452.35 & 43.04 \\
\hline $03-04$ & 285 & 2907.68 & 828688.80 & 265167.33 & 32.00 & 286624.50 & 34.59 \\
\hline $04-05$ & 285 & 2996.57 & 854022.45 & 347063.03 & 40.64 & 441826.95 & 51.73 \\
\hline $05-06$ & 285 & 3000.72 & 855205.20 & 307184.40 & 35.92 & 467351.55 & 54.65 \\
\hline $06-07$ & 285 & 4498.86 & 12821 & 435 & 33.94 & 609587.93 & 47.5 \\
\hline $07-08$ & 285 & 3991.49 & 1137574.65 & 536354.80 & 47.15 & 625840.05 & 55.02 \\
\hline $08-09$ & 285 & 4499.46 & 2823 & 4893 & 38.16 & 498868.28 & 38.9 \\
\hline $09-10$ & 285 & 4499.64 & 1282397.40 & 596357.28 & 46.50 & 741397.58 & 57.81 \\
\hline $10-11$ & 285 & 4499.63 & 1282394.55 & 633962.08 & 49.44 & 839862.23 & 65.4 \\
\hline $11-12$ & 285 & 4489.91 & 1279624.35 & 636650.10 & 49.75 & 795255.45 & 62.15 \\
\hline $12-13$ & 285 & 4499.22 & 1282277.70 & 644940.75 & 50.30 & 846140.78 & 65.99 \\
\hline 13-14 & 285 & 4499.91 & 1282474.35 & 592021.48 & 46.16 & 826836.30 & 64.47 \\
\hline 14-15 & 285 & 5739.44 & 1635740.40 & 485561.15 & 29.68 & 763730.18 & 46.69 \\
\hline $15-16$ & 285 & 5739.37 & 1635720.45 & 597758.53 & 36.54 & 813317.33 & 49.72 \\
\hline $16-17$ & 285 & 4499.31 & 1282303.35 & 631659.28 & 49.26 & 763701.68 & 59.56 \\
\hline $17-18$ & 285 & 4499.19 & 1282269.15 & 567574.18 & 44.26 & 665392.35 & 51.89 \\
\hline 18-19 & 285 & 3999.58 & 1139880.30 & 578773.25 & 50.77 & 678328.50 & 59.51 \\
\hline $19-20$ & 285 & 4800.76 & 1368216.60 & 676969.05 & 49.48 & 933581.63 & 68.23 \\
\hline $20-21$ & 285 & 3999.74 & 1139925.90 & 636566.03 & 55.84 & 883494.30 & 77.50 \\
\hline $21-22$ & 285 & 3999.69 & 1139911.65 & 434595.08 & 38.13 & 734030.33 & 64.39 \\
\hline $22-23$ & 285 & 3999.54 & 1139868.90 & 517817.93 & 45.43 & 584687.48 & 51.29 \\
\hline $23-24$ & 285 & 3892.89 & 1109473.65 & 560753.65 & 50.54 & 798065.55 & 71.93 \\
\hline \multicolumn{3}{|c|}{ Average Value } & 1164477.23 & 505544.40 & 43.29 & 664303.18 & 56.93 \\
\hline
\end{tabular}




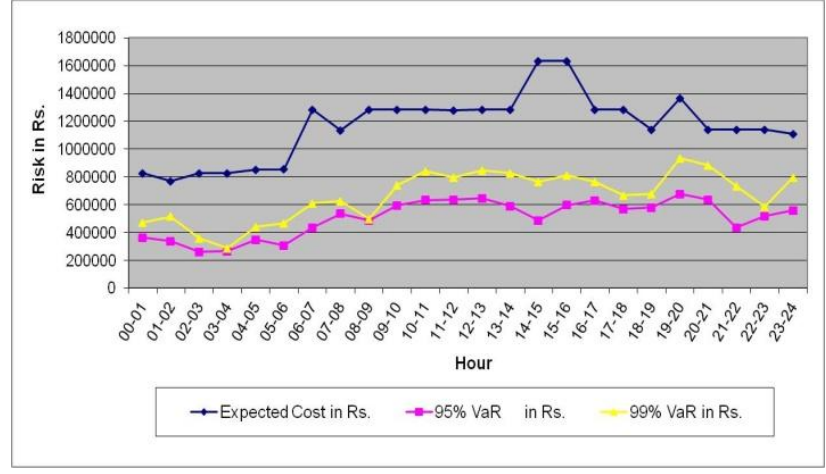

Fig. 5: CVaR for $10 \mathrm{MW}$ Purchase from Exchange for $1^{\text {st }}$ April 2010.

\section{CONCLUSION}

Power trading is an integral aspect of competitive power markets. By efficiently managing risk, energy trading helps to ensure reliable electricity at stable prices, and promotes transparent energy markets.

In this paper risk due to price volatility is discussed with reference to Indian Electricity Market. Using the data of market clearing prices (MCP) \& market clearing volume (MCV) available on Indian Energy Exchange (IEX) and Power Exchange India Limited (PXIL), the risk is evaluated at each hour using Value at Risk (VaR) \& Conditional Value at Risk $(\mathrm{CVaR})$ method. The assessment of risk is important task of risk management. The VaR \& $\mathrm{CVaR}$ method gives monetary value of risk enabling utilities to hedge risk.

\section{REFERENCES}

[1] Min Liu, Felix F. Wu, Fellow, "A Survey on Risk Management in Electricity Markets" presented in the Proc. IEEE Power Eng. Soc. General Meeting Montreal, QC, Canada, 2006.

[2] R. Dahlgren, C. C. Liu, and J. Lawarree, "Risk assessment in energy trading," IEEE Trans. Power Systems, vol. 18, Issue 2, pp. 503-511, May 2003.
[3] Mario V.F. Pereira, M. F. McCoy, and H. M. Merrill, "Managing risk in the new power business," IEEE Computer Applications in Power, vol. 13, Issue 2, pp. 18-24, April 2000.

[4] J. L. Higle, and S. W. Wallace, "Managing risk in the new power business: a sequel," IEEE Computer Applications in Power, vol. 15, Issue 2, April 2002.

[5] Prabodh Bajpai and S. N. Singh, "Electricity Trading In Competitive Power Market: An Overview And Key Issues", International Conference on Power Systems in Kathmandu, Nepal, pp 571 - 576, Nov. 3-5, 2004.

[6] S. J. Deng And S. S. Oren, "Electricity derivatives and risk management", Energy 31 (2006) 940-953 (www.elsevier.com/locate/energy)

\section{AUTHOR'S PROFILE}

Sandeep Chawda has completed his B.E. in Electrical Engineering from Rajive Gandhi Technical University, Bhopal, in 2006. He has completed M.E. in Power System in 2010 from University of Pune. Currently he is working as Assistant Professor and Head, Electrical Engineering Department in JSPM's Bhivarabai Sawant Institute of Technology \& Research (For Women), Wagholi, Pune. His area of interest includes Power Market, Renewable Energies, Power Electronics.

Dr. (Mrs.) S. R. Deshmukh has completed her B.E. in Electrical Engineering from Kolhapur University, in 1996. She has completed M.E. in Power System in 2002 from University of Pune. She has been awarded to Doctorate Degree in 2012 by University of Pune. Currently she is working as Assistant Professor in Electrical Engineering Department at PVG's College of Engineering \& Technology, Pune. Her area of interest includes Power System Operation \& Control, Application of Artificial Neural Network (ANN) to Power System. 